\title{
Changing health behaviors through the medical interview
}

\author{
SAMUEL M. PUTNAM \\ Boston University School of Medicine, \\ East Boston Neighborhood Health Center, Boston (MA), USA
}

I am writing this editorial from three perspectives: as a primary care physician searching for an alternative to the fruitless admonishment of patients to abandon their destructive health behaviors; as a teacher trying to instill new attitudes and skills related to medical interviewing; and as an investigator looking for ways to understand how patient-physician interactions affect health outcomes especially in the area of behavioral change. What follows is a selective review of the literature on the clinical evidence supporting recent theories of behavioral change that I have found helpful in guiding my endeavors.

There is ample evidence that changing health behaviors is an important part of the physician's role, especially that of the primary care physician. McGinnis \& Foege (1993) have estimated the most proximate causes of death in the United States in 1990 and shown that tobacco use, poor diets together with physical inactivity, and alcohol abuse accounted for $19 \%, 14 \%$ and $5 \%$, respectively, of total deaths in that year. In five cohort studies, the age-adjusted relative risk of death from cardiovascular disease is substantially lower $(0.08$ to 0.28 ) for middle-aged men and women who have a serum cholesterol $<200 \mathrm{mg}$ per deciliter, who are nonsmokers, whose blood pressure is less than 120/80, who have a normal EKG, who are not diabetic, and who have no history of myocardial infarction. Their life expectancy was also 6 to 10 years longer (Stamler et al. 1999). Finally, the decrease in morbidity and mortality

Address for correspondence: Professor S.M. Putnam, 1572 Massachusetts Avenue Apt. 40 Boston, Massachusetts 02138-2911 (USA).

Fax: +1-617-568.4510

E-mail: smp13@attbi.com in the US from heart disease has been attributed more to people modifying their smoking, dieting, and exercising behaviors than to direct medical interventions such as treatment of hypertension or ischemic heart disease (Goldman \& Cook, 1984).

There is also evidence that physicians can be effective in helping patients to change health behaviors. In one of the earliest studies of attempts by physicians to decrease patients' smoking, Russell showed in a randomized control trial that when primary care physicians told their patients who smoked "Smoking is bad for your health, I strongly recommend you stop," $3.1 \%$ of their patients were no longer smoking at the end of a year in comparison to $0.3 \%$ of smokers who were not given this advice (Russell et al. 1979).

As a busy practitioner, it is very tempting to simply scold patients for smoking, eating too much, or drinking too much. However, practical experience has shown that this approach does not work (Miller et al. 1999). In fact, the theory of "reactance" by Brehm suggests that patients may respond to this approach by doing just the opposite of what the physician tells them. Brehm (1966) postulates "a restriction of feelings of choice produces a negative motivation state... When this occurs, the person is motivated to restore his lost freedom and to regain his sense of control. This type of reaction might help to explain why patients sometimes act against what appears to be their own best interests by leaving the hospital or quitting treatment against medical advice.... This suggests that if health care professionals use words like 'must,' 'should,' and 'have to,' they may arouse reactance in their patients and therefore reduce acceptance." (quoted from Stone, 1980). Patterson and Forgatch's research confirms this theory (Patterson and Forgatch, 1985). In family therapy sessions, the counselors alternated 12-minute blocks of directive- 
confrontational counseling with supportive-reflective counseling. Patients responded by showing increased resistance during the former and decreased resistance during the latter. Miller et al. (1993) tested this again with volunteers for a free "Drinker's Check-Up".

This program was a two-hour evaluation of a person's risk of having alcohol related problems followed by a counseling session. The two-hour evaluation consisted of neuro-psychological tests and various biological measurements. For the counseling session, volunteers were randomly assigned to receive feedback about the test results in a "client-centered" session or a "directive" session (1/3 of the volunteers acted as controls by receiving the "Drinker's Check-Up" six weeks later). The counselors who conducted the feedback sessions were trained to use both methods. In the "clientcentered" sessions, the counselors used reflective listening skills, avoided confronting patients about their drinking, and focused on what negative effects the clients thought drinking might be having and what they wanted to do about it. In the "directive" sessions, the counselors deliberately confronted the clients' resistance to the evidence that they had a drinking problem, gave advice, and disagreed with clients' attempts to minimize their problem. All these sessions were tape-recorded, transcribed and coded. The volunteers were followed up at 6 weeks and 1 year to determine their drinking behaviors (assessed by a questionnaire and interviews with two significant others to corroborate the volunteers' answers). Analysis of the tape recordings showed that the counselors did appropriately vary their feedback styles, although the intervention (directive vs. clientcentered feedback) failed to produce a significant difference. However, when all the interviews were considered together, there were significant correlations between the frequency of specific coded behaviors and the amount of drinking patients reported at 12 months. Counselor confrontations (defined as responses that were challenging, disagreeing, head-on disputes, incredulity, emphasizing negative client characteristics, and sarcasm) were positively correlated with drinking 12 months after the intervention $(r=0.65, p<.001)$. Client responses that were interrupting, arguing, off-task (inattention, silence, or sidetracking), negative (blaming others, disagreeing, excusing, claiming impunity, minimizing, pessimism, and expressed reluctance or unwillingness to change) were also positively correlated with more drinking $(\mathrm{r}=.45-.65, \mathrm{p}<.01$ to $\mathrm{p}<.001)$. It is noteworthy that these negative client responses represented less than $3 \%$ of the total client behaviors. In fact, the absence of these behaviors correlated more strongly with the outcomes than their presence. Thus, by avoiding confrontations and preventing negative client responses, counselors are likely to induce behavioral changes.

I have found two recent theories on behavioral change to be helpful in directing my clinical and teaching efforts in "motivational interviewing." The first is the theory of Transtheoretical Model of Change developed by Prochaska and Di Clemente. These investigators studied people who have changed problem behaviors such as smoking, drinking, using drugs, etc. without help from counselors in order to determine the natural history of the process. They found that people pass through 4 stages of change. The first they call precontemplation where people are either unaware that their behavior is a problem or are unwilling or uninterested in changing. The second is the stage of contemplation where people realize they have a problem but have not decided if they want to commit themselves to making a change. The third stage is one of action where people actually change their behaviors. The final stage is one of maintenance where people struggle to keep themselves committed to their changed behavior. Using validated questionnaires these investigators and their colleagues have shown that people coping with many different problems - alcoholism, drug addiction, smoking, physical inactivity, even juvenile delinquency - fall into one of these stages and can be shown to progress through the stages with or without the help of therapists (Prochaska et al., 1994). Table I illustrates the prevalence of people's location in the different stages of change for different problems.

The stages of change actually form a cycle. People, for reasons that they often do not understand, will slip back a stage or relapse after being in the maintenance phase. In fact, most people will cycle through these stages many times before making a permanent change. An adaptation of Prochaska and Di Clemente's model diagram (figure 1) that I use includes a relapse phase to illustrate to my patients that I expect they will relapse. I tell them that relapses in their behavior is a natural part of the process of making a permanent change and that I want to work with them as they get ready to start the cycle again. I believe this helps them understand that relapse is part of the process of change and not a "failure" on their part.

Patients, as they go through this cycle, think about their problem behavior differently as they go through each stage and therefore will respond to different counseling techniques. In a study of smokers, participants were randomly allocated to four different interventions and were asked at 6,12 and 18 months 
Table I. Distribution of sample population between stages of change in studies of problem behaviours.

\begin{tabular}{lccccc}
\hline Study Pop & Total N & Precontemplation & Contemplation & Action & Maintenance \\
\hline Smoking Cessation & 764 & 108 & 187 & 134 & 247 \\
Quitting Cocaine & 156 & 8 & 15 & 62 & 18 \\
Weight Control & 123 & 18 & 65 & 22 & 41 \\
Adolescent delinquency & 159 & 29 & 46 & 17 & 114 \\
Safer Sex & 213 & 94 & 58 & 102 & 80 \\
Condom use & 345 & 131 & 18 & 10 & 60 \\
Sunscreen unse & 227 & 119 & 24 & 26 & \\
Mammography Screening & 141 & 31 & & & \\
\hline
\end{tabular}

Adapted from Table 1, Prochaska et al., 1994, p. 41.

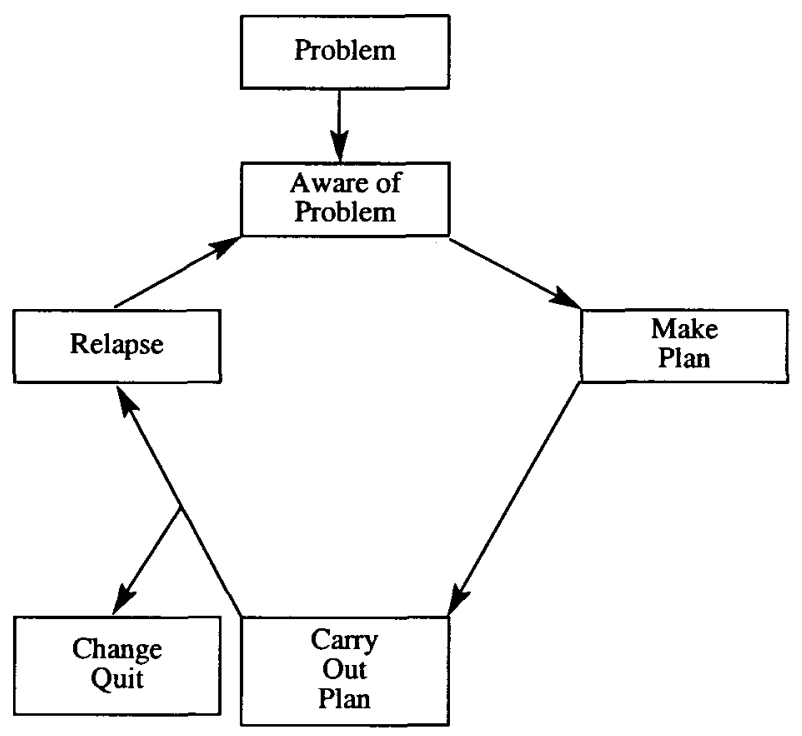

Figure 1. - Stages of Change (adapted from Prochaska, 1984).

about their smoking (Prochaska et al., 1993). The first intervention consisted of participants receiving a manual that provided information about the health effects of smoking and ways to quit. The second consisted of a manual that was specifically tailored to the participant's stage of change. In the third intervention, in addition to the receiving a tailored manual, participants received feedback during the study about the progress they had made in achieving the goals that they had set in quitting. Computers generated the feedback based on participant reports and presented it in a completely neutral fashion e.g. progress in relationship to participants' stated goals and in relationship to others in the same stage. In the fourth intervention, participants received the manual, neutral feedback, and counseling over the telephone by a trained counselor. The results are shown in figure 2 . Each intervention, except the last, resulted in

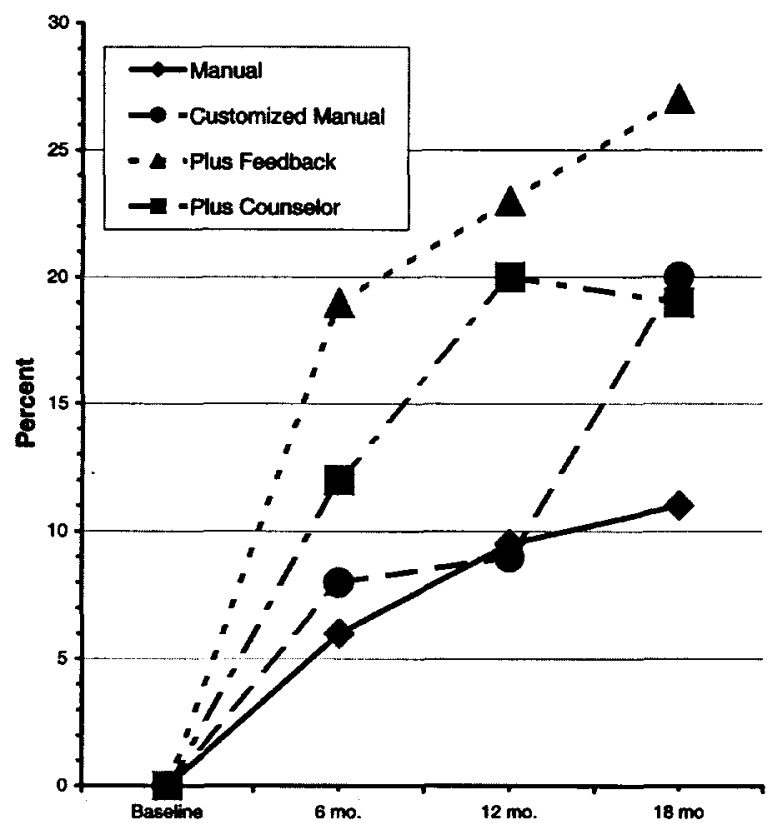

Figure 2. - Smokers Who Quit (Prochaska et al., 1993).

incremental increases in abstinence rates. Thus, a manual customized to the participant's particular stage of change was better than a booklet giving general information about smoking. Adding neutral feedback to this customized manual increased abstinence rates even more. However, in the group receiving the customized manual, feedback, and counseling, the abstinence rate actually regressed during the study. Unfortunately, the telephone counseling was not tape recorded, but the counselors said that they might have pressured participants to abstain, lending support to the theory of reactance (see above).

The research of Deci, Ryan and Williams supports another useful theory for understanding how patients 
change health behaviors. This theory, called Self Determination, states that human beings evolve by seeking to meet challenges in response to internally generated forces rather than in response to external rewards and punishments as advocated by the operant theorists (Deci, 1990). The theory is called "selfdeterminant" because it stresses the importance of the individual's choice to pursue goals as the individual evolves. The motivation is "intrinsic" and therefore not dependent upon outside forces. Outside forces may affect the development of motivation, e.g. rewards, punishments, or imposed values. However, research has shown that this "controlled" motivation is less potent than the "autonomous" or "self-determined" brand. Two important factors do influence the development of "autonomous" motivation. Significant others can support the development of autonomous motivation by acknowledging and supporting the individual's right to choose, by encouraging the individual's initiatives, and supporting the individual's decisions. Significant others can also abort the development of autonomous motivation by exerting pressure on an individual to behave in a certain way, by being judgmental, etc. Another factor is the degree to which individuals successfully meet challenges that arise from their intrinsic motivation to change and grow. Success builds competence, which, in turn, builds autonomous motivation.

Williams has tested this model among patients with diabetes, and patients who smoke. He followed 128 diabetics over a year as they went through routine care in a diabetic clinic (Williams et al., 1998). The patients completed questionnaires that measured: 1 . the degree to which they felt their motivation was "intrinsic" vs. "controlled;" 2. the degree to which they felt that the clinic staff supported their autonomous decisions; 3 . their perceived competence in managing their diabetes. The outcome measure at the end of the year was the amount of change in the patient's hemoglobin AlC; the lower this number, the better controlled was the patient's diabetes. As predicted (see figure 3), path analysis showed that the more patients perceived their providers to be "autonomy supportive," the more likely they were to become autonomously motivated. Likewise, the more autonomously motivated patients were, the more likely patients were to feel competent in managing their diabetes. Finally, the more competent patients felt, the more likely they were to control their diabetes as measured by the hemoglobin A1C. These relationships remained significant after controlling for all significant variables such as type and severity of diabetes, gender, etc.

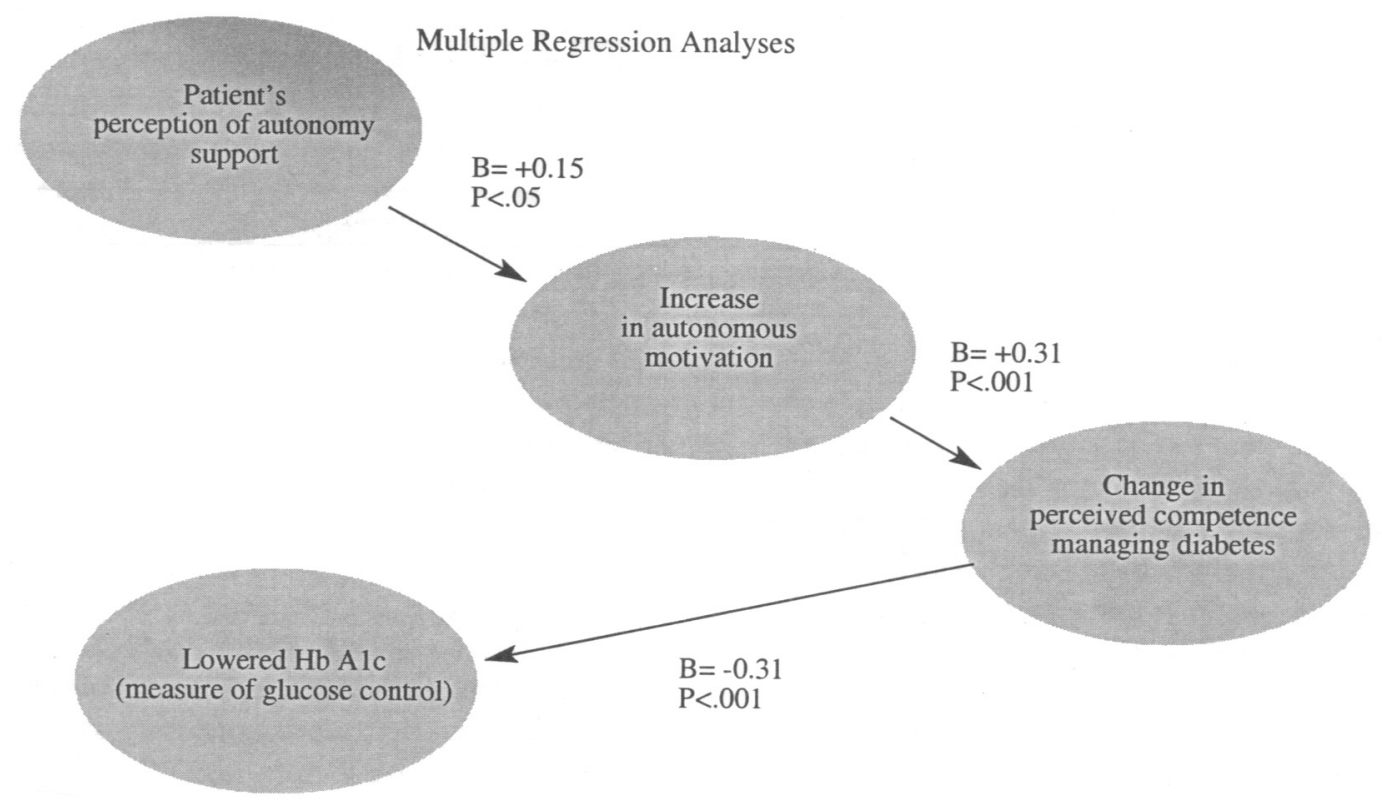

Figure 3. - Supporting autonomy to motivate patients with diabetes for glucose control (from Williams et al., 1998). 
Because this was an observational study, it could not be proved that autonomy support caused greater autonomous motivation, which in turn increased perceived competence and ultimately better control of diabetes. To test a causal hypothesis, Williams designed another study in which physicians used an "autonomy supportive" style of counseling vs. a "controlling" style (Williams \& Deci, 2001). In place of perceived competence, Williams looked at the degree to which patients varied in their participation in the interaction. He chose this variable because Kaplan et al, have shown that when patients are given information about their illnesses and are coached to ask questions during their visits to the physician, they participate more in the discussion during the office visit and have better outcomes of care, e.g. better control of their blood pressures and diabetes (Kaplan et al., 1989). Williams reasoned that the same relationship would hold with respect to non-smoking during a visit in which patients and physicians discussed smoking behaviors.

In this study, the physicians, before seeing the patients, opened a sealed envelope that randomly assigned the patient to the "autonomy supportive" or the "controlling" counseling method. Table II describes the differences in these styles. For both styles, the content of the counseling message was the " 4 -A's" model developed for the National Cancer Institute's initiative to decrease smoking in the American public. All counseling sessions were tape-recorded. Trained coders, who did not know what counseling style had been assigned to the patient, rated physicians' counseling behaviors. Patients completed questionnaires about their smoking 6,12 , and 30 months after the counseling intervention. A carbon monoxide breath test was used to verify the non-smoking status of patients who said they had quit. The outcomes of the study were continuous abstinence at the end of 30 months, the number of days since last cigarette, and the longest number of days without smoking after the counseling intervention.

The intervention did not produce significant differences in the outcomes. However, when all the interviews were combined, ratings of the physician's "autonomy supportiveness" predicted the amount of patient involvement in the discussion which, in turn, predicted smoking behavior, Thus, the more actively involved patients were in the discussion, the more likely they were to change their smoking behaviors. Williams believes that the intervention itself failed to produce a difference for the following reasons: 1 . The physicians were given very brief training; 2 . When the physicians used the autonomy supportive style, they often left out clear "advice" to stop smoking - $10 \%$ of the time in the autonomy supportive intervention vs. $2 \%$ of the time in the controlling style, a difference that was not statistically significant $(\mathrm{p}<0.06)$. Williams hypothesizes that patients who were not "advised" to stop smoking did not receive a strong message about the importance of quitting. 3. Seventy-five percent (75\%) of the patients saw their own primary care physician. Williams speculates that the effect of the intervention may have been attenuated for patients seeing their own physician since patients may have been more influenced by their previous experience with their physician's interaction style than they were by the assigned style. Since the physician's "native style"

Table II. - 4-A's Model for Stopping Sinoking.

\begin{tabular}{|c|c|c|}
\hline & Autonomy Supportive & Controlling \\
\hline Ask & $\begin{array}{l}\text { How much, how long } \\
\text { Likes about smoking } \\
\text { What concerns } \\
\text { Previous attempts to quit }\end{array}$ & $\begin{array}{l}\text { How much, how long } \\
\text { Elaborates health risks }\end{array}$ \\
\hline Advise & $\begin{array}{l}\text { Clear } \\
\text { Not pressured } \\
\text { Acknowledge patient choice } \\
\text { Feelings about advise }\end{array}$ & $\begin{array}{l}\text { Forceful } \\
\text { No acknowledgement of patient choice }\end{array}$ \\
\hline Assist & $\begin{array}{l}\text { Ask if ready to quit } \\
\text { If so, what date } \\
\text { If not, what needs to happen } \\
\text { Inform about methods or } \\
\text { Encourage to think about it } \\
\text { Given booklet }\end{array}$ & $\begin{array}{l}\text { Advised to set quit date } \\
\text { Prescribed patch } \\
\text { Given booklet }\end{array}$ \\
\hline Arrange & $\begin{array}{l}\text { Suggest follow-up visits or } \\
\text { telephone contact }\end{array}$ & $\begin{array}{l}\text { Told to make appointment for follow-up } \\
\text { visit or telephone contact }\end{array}$ \\
\hline
\end{tabular}

Adapted from Williams et al., 2001. 
of counseling was not determined (through tape recordings of pre-intervention visits), it was not possible to include this variable in the analyses. 4 . Williams suggests that autonomy supportive counseling may require a longer period of time to achieve its results than the controlling style. In fact, the strong directive influence of the controlling style may achieve better short-term results, but produce more relapses. The autonomy supportive style, on the other hand, may make better use of patient relapses than the controlling style through its non-judgmental style and its encouragement for patients to choose their own path at their own pace. While it is disappointing that this randomized, controlled trial of a theoretically driven intervention did not achieve significant results, Williams' explanations of the trial's weaknesses and the associations of autonomy supportive counseling styles with the outcomes convinces me that the theory merits further attention.

As a teacher, I am interested if, and how, physicians can be taught to use skills that will encourage patients to change their health behaviors. In three studies in the United States, Fleming et al have trained physicians to use brief counseling interventions for their primary care patients to reduce their alcohol consumption (Fleming $e t$ al., 1997; 1999; Manwell et al., 2000). Using role playing, trainers teach the physicians in a short training session and at least two booster sessions in the succeeding months how to counsel their patients. The physicians apply the counseling interventions, only 10 15 minutes in length, one month apart. In the three studies - of adults, older adults, and young pregnant women - the patients who received the counseling intervention reduced their drinking behaviors approximately two times more then controls at six and twelve months. In one of the studies, patients also made fewer emergency room visits, and used fewer hospital days than controls (Fleming et al., 1997). Williams has also shown that if I use the theory of self determination to guide my teaching, my teaching is likely to be more effective. In an elegant study of medical students in a required course on medical interviewing, Williams followed the students for two years and monitored their autonomous motivation for learning, the value they ascribed to the psychosocial aspects of medical care, and their perceived competence in medical interviewing (Williams \& Deci, 1998). He also asked them to rate their instructors on the degree to which their teaching styles were "autonomy supportive" as opposed to "controlling." Over the course of the two years, Williams found significant correlations $(r=0.3$ to 0.4$)$ between students' autonomous motivation and how "autonomy supportive" they perceived their instructors to be. He also noted significant correlations between students' autonomous motivation and the value they placed upon psychosocial medicine and between their autonomous motivation and their perceived selfcompetence. These relationships persisted through the end of the 2-year study. Furthermore, when students were tested 6 months after the interviewing course, their skills in supporting their patients' autonomous motivation were significantly correlated $(r=0.42)$ with the degree to which they (the students) felt autonomously motivated.

Finally, as an investigator of the medical interview, I am interested in defining specific verbal behaviors that have an impact on patients' efforts to change their behaviors. In an effort to broadly define the objectives and tasks of the medical interview, (Bird \& Cohen-Cole, 1990) and later Lazare et al. (1995) have described the three functions of the medical interview - data gathering, relationship building, and educating the patient/negotiating the treatment plan. Most of the research on patient-physician interactions at the microlevel has focused on how physicians uncover patient concerns, improve patient satisfaction, and develop better relationships, i.e. the first two functions (Stewart, 1995). There has been much less research on specific behaviors related to the physician tasks of education and negotiation of a treatment plan. More importantly, most of the research on patient-physician interactions has focused on how physician behavior affects the interaction. A few investigators have looked at how patients try to affect the interview process. Tuckett showed that patients attempt to inject their own ideas into the interaction in $84 \%$ of the visits studied but most of the time, physicians cut-off or ignore their attempts, leaving the patients frustrated and disinclined to follow the physicians' treatment plans (Tuckett, 1986; Tuckett \& Williams, 1984). I have already cited Kaplan's work on teaching patients to participate in the discussion about their medical care. In another study, Cegala et al. (2000) sent patients a few days before their office visit a booklet that gave practical suggestions on how to participate in the discussion at their visit, e.g. listing symptoms, listing expectations, etc. These patients, in comparison to controls, took more control of the interview, obtained more information from physicians and in turn provided more information about their illness.

These studies strongly suggest that patients want to express their own ideas about their illnesses, want to participate in the decision making processes, and want to get feedback about their progress in managing their illnesses. These attributes of wanting to play a more 
active role in the medical interview are certainly crucial to the development of autonomous motivation as opposed to "controlled" motivation. By conducting more research on the actual behaviors that take place between patients and physicians when they discuss behavioral change, we may be able to learn more about the specific behaviors we can teach students and patients.

In summary, I have found that the theories of Prochaska and Di Clemente and Ryan and Deci provide a model I can use in counseling patients on behavioral change that has more supporting evidence than the instinctive "scolding" model. First, it is useful to make the assumption that patients want to change and have the intrinsic motivation to do so. This reminds me that I do not motivate patients - patients motivate themselves. I can help them if I support their choices, encourage them to participate in their care by "brainstorming" on possible behavior-change plans, and help them make choices that enhance their sense of competence. If I use harsh, judgmental, authoritarian words, as I am tempted to do in moments of frustration and fatigue, I waste my time because the results will be the opposite of what I want.

Second, it is useful as a clinician to consider the epidemiology of behavioral change as demonstrated by Prochaska and Di Clemente. Their model shows that people go through different stages in the process of changing behaviors. They do not suddenly go from learning they have a problem to carrying out a plan for solving it. Because the process has well defined stages in which patients think differently about their problem, I need to act differently and use different resources at each stage. Furthermore, the process is usually cyclical as patients make, carry out, and fail different plans. By considering its "epidemiology," I can approach the problem of behavioral change as I would any clinical problem by determining where the patient is in the cycle and what approaches might be used to treat the problem. Furthermore, I can treat a relapse in the same way I would approach a relapse in any chronic condition non-judgmentally (it is not useful to blame patients for a relapse of their cancer) and reflectively (what can the patient and I learn about the previous treatment that might have led to the relapse).

Finally, using the data that show patients who participate in their care have better outcomes, I can encourage - perhaps even provoke - the patient into actively participating in the discussion about their treatment. I have found the model developed by the Bayer Institute for training physicians on counseling methods for behavioral change to be useful in selecting strategies for a particular patient (Bayer Institut, 1996). By asking patients how strongly they belief the particular behavior they are trying to change affects their health ("Commitment") and how confident they are that they can change their behavior (a measure of perceived competence), one can construct a $2 \times 2$ table (table III). Ideally, I want to have all my patients in the box representing high commitment and high confidence since these patients are most likely to change. For patients who are low in commitment, I can provide information, point out discrepancies between goals and current activities, and elicit costs and benefits of changing vs. staying the same. For patients low in confidence, I can ask patients about their previous experiences in changing unwanted behaviors, encourage small "do-able" steps, and support autonomous decisions by soliciting and encouraging choices that patients can make.

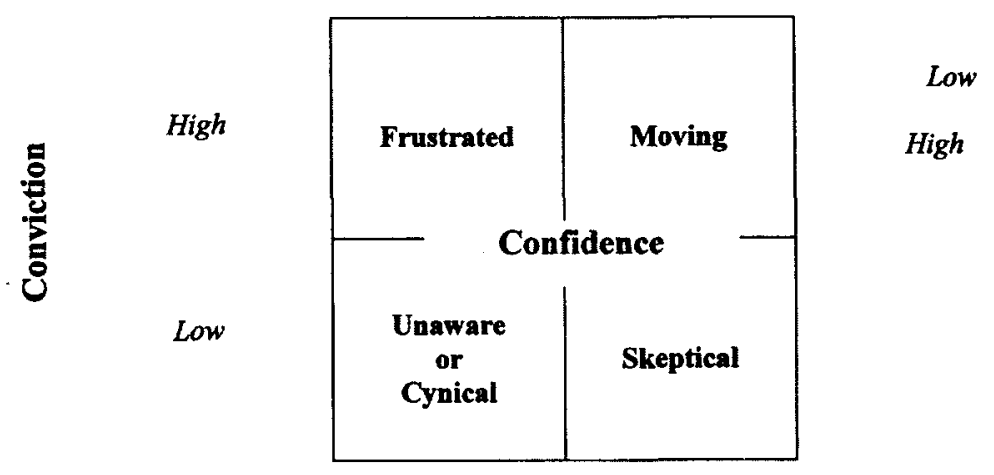


George Engel, one of the most important teachers and investigators in the field of patient-physician communication, long ago pointed out that the medical interview was the physician's most important instrument (Engel, 1973). Research over the past forty to fifty years has certainly supported this idea. Fortunately, as the evidence grows, medical institutions are beginning to focus more attention on developing interviewing skills in their trainees. With the increasing importance of changing health behaviors, investigators and teachers need to turn more attention to this area.

\section{REFERENCES}

Bayer Institute for Health Care Communication (1996). Choices and Changes Workbook. Bayer Institute for Health Care Communication: West Haven, CT.

Bird J. \& Cohen-Cole S.A. (1990). The "three function model" of the medical interview: an educational device. Advances in Psychosomatic Medicine 20, 65-88.

Brehm J. (1966). A Theory of Psychological Reactance. Wiley: New York.

Cegala D.J., McClure L., Marinelli T.M. \& Post D.M. (2000). The effects of communication skills training on patients' participation during medical interviews. Patient Education and Counseling 41, 209-222.

Deci E.L. \& Ryan R.M. (1990). A motivational approach to self-integration in personality. Nebraska Symposium on Motivation 38, 237-288.

Engel G.L. (1973). "The Best and the Brightest": the missing dimension in medical education. Pharos 36, 129-133.

Fleming M.F., Barry K.L., Manwell L.B., Johnson K. \& London R. (1997). Brief physician advice for problem alcohol drinkers: a randomized controlled trial in community-based primary care practices. Journal of American Medical Association 277, 1039-1045.

Fleming M.F., Manwell L.B., Barry K.L., Adams W. \& Stauffacher E.A. (1999). Brief physician advice for alcohol problems in older adults: a randomized community-based trial. Journal of Family Practice 48 (5), 378-384.

Goldman L. \& Cook EF. (1984). The decline in ischemic heart disease mortality rates: an analysis of the comparative effects of medical interventions and changes in lifestyle. Annuals of Internal Medicine 101, 825-836.

Kaplan S.H., Greenfield S. \&Ware J.E.J. (1989). Assessing the effects of physician-patient interactions on the outcomes of chronic disease. Medical Care 27, S110-127.

Lazare A., Lipkin M. \& Putnam S.M. (1995). Three functions of the medical interview. In The Medical Interview (ed. M. Lipkin, S.M. Putnam and A. Lazare), pp. 3-19. Springer-Verlag: New York.

Manwell L.B., Fleming M.F., Mundt M.P., Stauffacher E.A. \& Barry K.L. $(2000)$. Treatment of problem alcohol use in women of childbearing age: results of a brief intervention trial. Alcoholism: Clinical and Experimental Research 24 (10), 1517-1524.

McGinnis J.M. \& Foege W.H. (1993). Actual causes of death in the United States. Journal of American Medical Association 270, 2207-2212.

Miller W.R., Benefield G. \& Tonigan J.S. (1993). Enhancing motivation for change in problem drinking: a controlled comparison of two therapist style. Joumal of Consulting and Clinical Psychology 61, 455-461.

Miller W.R., Meyers R.J. \& Tonigan J.S. (1999). Engaging the unmotivated in treatment for alcohol problems: a comparison of three strategies for intervention through family members. Journal of Consulting and Clinical Psychology 67 (5), 688-697.

Patterson G.R. \& Forgatch M.S. (1985). Therapist behavior as a determinant for client noncompliance: a paradox for the behavior modifier. Journal of Consulting and Clinical Psychology 53, 846-851.

Prochaska J.O. (1984). Systems of Psychotherapy. Dorsey Press: Homewood, IL.

Prochaska J.O., Di Clemente C.C., Velicer W.F. \& Rossi J.S. (1993). Standarized, individualized, interactive, and personalized self-help programs for smoking cessation. Health Psychology 12, 399-405.

Prochaska J.O., Wayne F., Velicer J.S.R., Rossi J.S., Goldstein M.G., Marcus B.H., Rakowski W., Fiore C., Harlow L.L., Redding C.A., Rosenbloom D. et al. (1994). Stages of change and decisional balance for 12 problem behaviors. Health Psychology 13, 39-46.

Russell M.A.H., Wilson C., Taylor C. \& Baker C.D. (1979) . Effect of general practitioners' advice against smoking. British Medical Journal 2, 231235.

Stamler J., Stamler R., Neaton, J.D., Wentworth D., Daviglus M.L., Garside D., Dyer A.R., Liu K. \& Greenland P. (1999). Low risk-factor profile and long-term cardiovascular and noncardiovascular mortality and life expectancy: findings for 5 large cohorts of young adult and middle-aged men and women. Joumal of American Medical Association 282 (21), 2012-2018.

Stewart M.A. (1995). Effective physician-patient communication and health outcomes: a review. Canadian Medical Association Journal $152,1423-1433$.

Stone G.C., Cohen F. \& Adler N.E. (1980). Health Psychology: a Handbook Jossey-Bass: San Francisco.

Tuckett D. \& Williams A. (1984). Approaches to the measurement of explanation and information-giving in medical consultations: a review of empirical studies. Social Science and Medicine 18, 571-580.

Tuckett D., Boulton M., Olson C. \& Williams A. (1986). Meetings Between Experts: an Approach to Sharing Ideas in Medical Consultations. Tavistock Publications: New York.

Williams G.C. \& Deci E.L. (1998). The importance of supporting autonomy in medical education. Annuals of Internal Medicine 129, 303-308.

Williams G.C. \& Deci E.L. (2001). Activating patients for smoking cessation through physician autonomy support. Medical Care 39, 813823.

Williams G.C., Freedman Z.R. \& Deci E.L. (1998). Supporting autonomy to motivate patients with diabetes for glucose control. Diabetes Care $21,1644-1651$. 